\title{
La inmigración como una prueba social y los márgenes legales del desencuentro. Políticas públicas, prácticas sociales y construcción de la persona
}

\author{
Marie José Devillard \\ Universidad Complutense de Madrid \\ mj.devillard@cps.ucm.es
}

Recibido: 28-10-2014

Aceptado: 15-09-2015

\section{Resumen}

La redacción de las directrices y los procedimientos administrativos que hacen virtualmente posible la inmigración, contribuyen a construir no sólo los itinerarios personales sino también el imaginario social sobre la alteridad. El principal objetivo de este artículo es poner de relieve -mediante el análisis discursivo de las Hojas informativas publicadas en la web del Ministerio de Empleo y Seguridad Social— cómo la construcción social del emigrante/inmigrante y el proyecto migratorio topan con unas representaciones y envites, instituidos y refrendados en y por la propia formulación de la reglamentación, pero no del todo explícitos. Entendiendo el texto como una acción que genera otras acciones, se examinan las consecuencias que tiene sobre la práctica social de los inmigrantes. En suma, se trata de vislumbrar los elementos (terminología, fórmulas, esquemas y prácticas inducidas) que van constituyendo al inmigrante como agente social subordinado a micro-procesos y relaciones que se le escapan en gran parte, y van marcando su propia capacidad de acción. En conclusión y retomando la distinción sugerida por Foucault entre 'principio de diferencia' y 'principio de indiferencia', se muestra que mientras el primero rige las cláusulas generales, el segundo articula las específicas.

Palabras clave: inmigración; reglamentación legal; micro-procesos; acción social; inserción social; identidad; antropología social. 


\title{
The Immigration as a Social Ordeal and the Legal Margins of Disagreement. Public Policies, Social Practices and the Construction of the Person
}

\begin{abstract}
The regulation of administrative principles and proceedings that tacitly made possible the immigration process enables not only certain personal itineraries but also the emergence of a social imaginary about the otherness. Based on the discursive analysis of the information sheets published online by the Department of Employment and Social Security in Spain, the main aim of this article is to highlight how the social construction of the emigrant/immigrant and his migratory project, have to face representations and challenges, which are simultaneously established and endorsed by the formulation of regulations itself, although they might not be completely explicit. I conceive regulations as actions that trigger other actions. As such, in this article I analyze the consequences that these regulations have upon the social practice of the immigrants. In sum, this article seeks to envisage the elements - terminology, analytic principles, images, practices - that constitute the immigrant as a social agent, subordinated to micro-process and relations of which he cannot account for, even if they shape its own capacity for action. In sum, and following Foucault's distinction between the principle of difference and the principle of indifference, I argue that the first one governs (regulates) general clauses whereas the second articulates specific ones.
\end{abstract}

Keywords: Immigration; Legal Regulations; Micro-process; Social Action; Social Insertion; Identity; Social Anthropology.

\section{Referencia normalizada}

Devillard, M.J. (2015): “La inmigración como una prueba social y los márgenes legales del desencuentro. Políticas públicas, prácticas sociales y construcción de la persona”, Política y Sociedad, 52 (3), pp. 897-920.

Sumario: 1. Introducción. 2. Presentación de la problemática de investigación. 3. Las cláusulas generales: la institucionalización de la diferencia. 4. Las cláusulas específicas: modelos culturales e inserción social. 5. Prácticas legítimas y procedimientos de contención de la inmigración. 6.Expectativas y lógicas culturales. 7. Conclusión. 8. Bibliografía.

$$
* * *
$$

\section{Agradecimientos}

La siguiente reflexión se inserta dentro del Proyecto de investigación (CS02011-25322) "Aproximación antropológico social de la vulnerabilidad y de los derechos humanos: inmigración, contextos sociales e institucionales". Si bien el trabajo de campo que he realizado ha tenido como escenario principal una zona semi-rural andaluza, el hecho de que el objeto analizado en este artículo esté constituido por normativas generales del Estado así como el carácter menor y general de las observaciones utilizadas a título complementario, no hacen necesario precisar más el contexto geográfico, económico y social específico. 
Between me and the other world there is ever an unasked question: unasked by some through feelings of delicacy; by others through the difficulty of rightly framing it. All, nevertheless, flutter round it. They approach me in a half hesitant sort of way, eye me curiously or compassionately, and then, instead of saying directly, How does it feel to be a problem? they say, I know an excellent colored man in my town; or, I fought at Mechanicsville; or, Do not these Southern outrages make your blood boil? (..)

(Du Bois W.E.B, The souls of Black folk)

\section{Introducción}

‘¿Qué impresión hace el ser un problema?’ pone Du Bois en boca de las personas bienpensantes que se cruzan con él, un negro, pero no cualquiera, sino un escritor y científico social. Por supuesto, al hablar de 'prueba de la inmigración' (Devillard, 2014) no se trata de evocar - desde un enfoque fácil y algo miserabilista - las (sin embargo indudables y lamentables) dificultades que los migrantes y candidatos (contemporáneos) a la inmigración a Europa han de superar. En cambio, el concepto resulta operativo analíticamente hablando si se considera el hecho de inmigrar como un «desafío histórico, socialmente producido, desigualmente distribuido» (Martuccelli, 2006: 12) que el outsider (Elias, 1965) tiene que afrontar. «La noción de prueba - propone Martuccelli- compromete al individuo en tanto que actor que se enfrenta con problemas y una representación de la vida social como constituida por una pluralidad de consistencias». Así definido, dicho concepto articula las acciones y las experiencias individuales - con sus contingencias y heterogeneidades - con las dimensiones estructurales que intervienen - de manera compleja y cambiante- en el fenómeno. Si bien, como nos enseñó Sayad (1999) la comprensión de las consecuencias tanto personales como colectivas hace imprescindible restituir ambas dimensiones, interna (situación en el país de procedencia) y externa (posición en la tierra de destino), la emigración/inmigración es, ante todo, para los protagonistas directos, un proceso prolongado cuya naturaleza y temporalidad exceden con creces los desplazamientos y las cuestiones de desterritorialización y, luego, de integración social en un país extraño, a las que una visión egocéntrica — replegada sobre la nación receptora - les reduce a menudo (Izquierdo, 2001). Plantear la inmigración como una «prueba» societal invita a tener en cuenta el nexo entre las acciones y las trayectorias personales de los inmigrantes (con las variantes que les singularizan en función de sus posiciones sociales y soportes) y los ámbitos sociopolíticos y jurídicos tanto propios como ajenos; pero incita también a enmarcar estos no solo dentro de las condiciones sociales que definen sus modalidades de ejercicio a nivel local en los lugares de partida y de llegada, sino también en el contexto económico internacional que ha producido y reproduce un estado crónico y perdurable 
de vulnerabilidad social y económica. El análisis debe evitar dos errores comunes al menos: la visión de corte nacionalista, centrada unilateralmente en las relaciones socioeconómicas y políticas internas (Sassen, 2001); y la concepción de sentido común que achaca la emigración a gran escala a «las condiciones de pobreza, desempleo y superpoblación por sí solas» (Gil Araujo, 2008) y que está en el origen de las imágenes —como la «invasión», el «aluvión»o la «catarata»—1 de procesos determinados por causas «objetivas» de orden económico o demográfico (Mezzadra, 2005: 44). La globalización, el contexto de la crisis económica actual, las desigualdades estructurales persistentes entre los distintos países, junto las políticas de corte neoliberal, el cuestionamiento del Estado de bienestar y el desliz de la política hacia un enfoque cada vez más penalista y represivo, unido a los conflictos armados que azotan a muchos países, constituyen los macromarcos, internacionales, que están en el origen de los fenómenos observables a nivel local en los países de inmigración. Por somera que sea la evocación de estos fenómenos, es imprescindible tenerlos presentes porque explican tanto la permanencia y amplitud de los procesos migratorios como la evolución de las políticas internas desarrolladas por los Estados receptores.

Pese a lo sugerente que resulta el hecho de proponer estudiar la ilegalidad para comprender nuestras representaciones de la legalidad, y debido a que el objetivo de este artículo es mucho más limitado, no se seguirá aquí a Foucault (2001[1982]: 229) a este respecto. Por el contrario, se propone explorar cómo el examen de los casos aparentemente menos gravosos, los que no parten a priori de una situación de ilegalidad ${ }^{2}$, permite también averiguar algunos de los problemas (menos visibles y conflictivos, ciertamente, que los afrontados por los 'ilegales' o 'sin papeles') que acechan a los inmigrantes en su intento de lograr una situación administrativa legítima (desde la perspectiva del país receptor) sin dejar de cumplir sus expectativas de vida, tanto personales como familiares o grupales. Por muy parcial que sea, una atención a los cauces que hacen posible, o imposibilitan, la regularización de la inmigración se nos presenta como un instrumento analítico que introduce a lo que Fassin y Morice (2001) califican como la 'existencia jurídica'. En las mismas fechas, Dubar (2002 [2000]: 214) también recalcó que la identidad para el inmigrante que vive en un país ajeno es 'primordialmente una cuestión de papeles y de puesta en marcha de leyes y reglamentos'. Sin embargo, lejos de limitarnos a lo que se podría interpretar banalmente como una constatación de hecho, se asume aquí que "el inmigrado, aquel del que se habla, no es en general más que el inmigrado tal como se lo ha constituido, tal como se lo ha determinado o tal como se lo piensa o define" (Sayad, 2010 [1999]: 253). Sirva, pues, la advertencia para recordar —en contra de cualquier tentación de naturalizar la cuestión — que uno

${ }^{1}$ Para una crítica de estas imágenes, véase Sami Naïr (2002) y Martínez Veiga (2011).

${ }^{2}$ Notemos sin embargo que los límites entre la ilegalidad y la legalidad son muy frágiles y se puede caer muy fácilmente desde una situación legal a una ilegal. 
no es un inmigrante sino que la sociedad receptora le constituye como tal, con connotaciones variables en función de diferentes constructos (raza, origen, lugar), contextos (socio-económicos y políticos), y sus múltiples. Mientras le cuesta a menudo al autóctono - mero ciudadano pero también, a veces, investigador - admitirlo, las personas procedentes de otros lugares (sobre todo si éstos han ocupado - y ocupanuna posición geopolítica subalterna) lo tienen muy presente, al menos experiencial si no, incluso, intelectualmente. Stuart Hall (1987), otro científico social negro, también expresó magistralmente en su texto 'Minimal selves' como la identidad negra no está dada de por sí y como su construcción corresponde a momentos históricos específicos: "también es un relato, un cuento, una historia; algo construido, enunciado, relatado y no algo con lo que uno se encuentra”. Pero también cabría mencionar a otras voces como, por ejemplo, las de Franz Fanon o también Aimé Césaire.

Con o sin ayuda externa ${ }^{3}$, hay una serie de tareas recurrentes y comunes que acompañan al proceso migratorio, tanto individual como familiar, y que incumben a los individuos (con o sin ayuda externa). Aunque estas cuestiones resulten muy importantes $^{4}$, la apuesta más directa de las páginas que siguen consistirá en reparar en los pasos administrativos que van siendo constitutivos del ad-venir, por-venir y ser del 'outsider' en el contexto nacional e internacional actual. Concretamente, se trata de poner de

${ }^{3}$ La legislación relativa a la inmigración no es solamente compleja y cambiante sino que, además, presupone para el sujeto un dominio de la misma y de la lógica administrativa, ajenos al ciudadano medio (no sólo extranjero), e implica unos saberes y una disciplina que a menudo se le escapa. Los 'servicios de información al inmigrante' puestos al alcance de los usuarios por algunos ayuntamientos constituyen, en este sentido, una respuesta y un recurso fundamentales para quienes no dispongan de las habilidades requeridas, no tengan acceso a la información (idiomática, jurídica...) o no tengan el manejo de las redes informáticas ministeriales, autonómicas y municipales. Como mínimo, allí donde dichos departamentos funcionan - y siempre que la plantilla y las competencias de los trabajadores lo permitan—, se facilita información y se deriva hacia otros recursos más competentes en la materia que es objeto de la petición; en el mejor de los casos, incluso, se acompaña al inmigrante durante gran parte del proceso, aconsejándole, buscando la respuesta adecuada en función de su situación objetiva, indicándole los requisitos y trámites a cumplir e, incluso, ayudándole a rellenar los formularios, pidiendo la 'cita previa' en su lugar, revisando su expediente antes de su entrega de modo a asegurar el mayor éxito posible teniendo en cuenta tanto la situación personal del solicitante como las condiciones de aceptabilidad en vigor, en cada momento. Allí donde se cuenta con tales servicios, el lugar en el que radiquen (céntricos o alejados, junto a otros servicios públicos o aislados), los días (todos o alguno(s) exclusivamente) y horarios (tarde o mañana) de apertura al público y la disponibilidad de sus trabajadores representan otros factores que dificultan o facilitan algunas de las innumerables cuestiones con las que se tropieza en la práctica. A falta de servicios públicos especializados que orienten a los inmigrantes, éstos dependen de sus redes personales (con los posibles riesgos que implican (malentendidos, desinformación, mafias...), de los servicios de gestorías (con su correspondiente coste adicional), o de instituciones dispersas y a menudo alejadas de su horizonte de intercomunicación y de su radio habitual de acción (residencia y trabajo) — por lo tanto, menos accesibles, más costosas, y caracterizadas por relaciones más formales e impersonales-.

${ }^{4}$ Dicha importancia radica sobre todo en que ponen en juego el sistema de disposiciones incorporadas así como los esquemas de acción de los agentes sociales que intervienen en el proceso. 
relieve cómo la construcción social del emigrante/inmigrante y el proyecto migratorio topan con un imaginario político, unas representaciones y unos envites, instituidos y refrendados en y por la propia formulación de la normativa, que no son explícitos.

Tras una breve introducción teórico-metodológica, se tratarán seguidamente los prerrequisitos generales de cuyo cumplimiento depende el inicio del proceso migratorio, los modelos de inserción que articulan las clausulas específicas y el examen de algunos procedimientos de contención de la inmigración. Se acabará la exposición con una comparación de las lógicas culturales distintivas a las que responden las actuaciones de los inmigrantes y de la administración frente a un mismo hecho.

\section{Presentación de la problemática de investigación}

El nivel de desarrollo de la legislación, así como los medios técnicos puestos al alcance del ciudadano, puede crear la ilusión de que éste dispone de una visión muy precisa tanto del campo de las posibilidades que le están abiertas como del modo de proceder. Ocurre lo mismo con respecto a las modalidades de inmigración. La consulta de la web de la Secretaría General de Inmigración y Emigración del Ministerio de Empleo y Seguridad Social da directamente acceso - entre otras cosas - a la normativa, los modelos de solicitudes y las 'hojas informativas' que orientan la política de extranjerías. Al dejar constancia, en particular, de las directrices y los procedimientos que hacen virtualmente posible la inmigración, la administración pública (y las instancias políticas) contribuye(n) a construir no sólo los itinerarios y las correspondientes prácticas sino también un imaginario social sobre la alteridad.

Las exigencias y circunstancias que se interponen entre los objetivos declarados (o no) y los requisitos oficiales, las acciones que median, se traducen en una determinada manera de identificar a los inmigrantes y de relacionarse éstos con los demás, tanto con los del grupo de pertenencia como con los del país de inmigración. Para estudiar esto, se propone - a título exploratorio - un análisis de las 'Hojas informativas' dirigidas a inmigrantes no comunitarios y colgados en dicha web', considerándolas 'como un

\footnotetext{
${ }^{5}$ Hay que recordar que el manejo de Internet está a la orden del día: la informatización de un número creciente de trámites constituye una apuesta pública conocida, y presentada como muy positiva. Para responder a esto, muchos ayuntamientos, sindicatos y asociaciones diversas ponen al alcance de los usuarios puntos de informática y cursos diversos destinados a aprender el manejo de ordenadores, Internet y demás redes sociales.

${ }^{6} \mathrm{Si}$ bien dichos materiales constituyen la principal fuente utilizada en este escrito, fue la observación de las dificultades y de las ambigüedades inherentes a su aplicación la que me ha incitado a prestar más atención a esta documentación. Decir también que, teniendo en cuenta los objetivos, he restringido el análisis a las autorizaciones que regulan el proceso de inmigración de personas procedentes de países no comunitarios: la '....inicial de residencia temporal no lucrativa'; la $\mathrm{n}^{\circ} 12$ : '...de residencia temporal por
} 
conjunto de acciones sobre acciones posibles' que 'opera sobre el campo de posibilidades adonde viene a inscribirse el comportamiento de sujetos actuantes: incita, induce, desvía, facilita o dificulta, amplia o limita, vuelve más o menos probable (..)' (Foucault 2001 [1982]: 238). Por consiguiente, se tratarán las 'Hojas informativas' como un catálogo de acciones (escritas) conducentes a que los agentes sociales se involucren o no en un proyecto migratorio, definiendo y/o excluyendo a quienes consideren que pueden hacerlo, dirigiendo sus pasos hacia un determinado proyecto de emigración-inmigración, imponiendo las condiciones, dictando la forma de llevarlo a cabo e incitando estrategias o resistencias a modo de respuestas. Asimismo se constatará cómo las expresiones contribuyen a construir de una manera metódica y naturalizante una imagen particular del candidato a la inmigración, tanto para consigo mismo como para con los demás (Dubar, 2002 [2000]). No obstante, al considerar el análisis sólo el texto, el desarrollo quedará limitado a la (potencial) inducción de las acciones ajenas debida a la mera enunciación (y cualidades conferidas por lo legal), y al alcance que dejan vislumbrar.

La finalidad del estudio consistirá, pues, menos en exponer la legislación existente (o desmenuzar sus detalles y complejidades) que en poner de relieve dos cuestiones: en primer lugar, una serie de operaciones verbales (analíticas y cognitivas) dirigidas, tanto al potencial inmigrante - al que está destinado directamente el texto- como, implícitamente, a un (supuesto) lector autóctono que pudiera facilitarle el proceso o, por el contrario, sentirse agraviado por la presencia de aquel; y, en segundo lugar, las consecuencias (acciones, imágenes sociales, conductas...) que esto tiene en la práctica social, en los propios interesados así como en la intervención de agentes externos. En tanto que tratamos de un dispositivo textual destinado a traducir la ley en hechos concretos y operativos, se asumen obviamente las dimensiones jurídicas del mismo. No obstante, lo que me interesa aquí concierne menos al marco legal que a como se difracta en dispositivos y actuaciones, los efectos que tiene sobre las prácticas, las representaciones y las relaciones sociales. Se trata fundamentalmente de vislumbrar en el escrito los elementos (terminología, categorizaciones, imágenes, acciones) que van constituyendo al inmigrante como agente social inevitable y (casi) permanentemente subordinado a micro-procesos, de los que no puede responder contrariamente a lo que pareciera sugerir el hecho de que sea titular de las demandas y principal interesado; el responsable de sus actos; el sujeto al que se aplican los requisitos; y, por último, el

reagrupación familiar’; $\mathrm{n}^{\circ} 16:$ ‘...de residencia independiente de familiares reagrupados'; $\mathrm{n}^{\circ} 17:$ ‘...de residencia y trabajo por cuenta ajena'; $n^{\circ} 25$ : '... de residencia temporal y trabajo por cuenta ajena de duración determinada de temporada o campaña'; $\mathrm{n}^{\circ} 35$ : ' $\ldots$ de residencia temporal por circunstancias excepcionales de arraigo laboral'; $\mathrm{n}^{\circ} 36$ : ' $\ldots$ de residencia temporal por circunstancias excepcionales, arraigo social'; $\mathrm{n}^{\circ}$ 46: '... de residencia temporal por circunstancias excepcionales, arraigo familiar'; así como las renovaciones de las autorizaciones, la $\mathrm{n}^{\circ} 15$ : ‘de residencia por reagrupación familiar'; y la $\mathrm{n}^{\circ}$ 18: 'de residencia temporal y de trabajo por cuenta ajena'. 
agente que tiene que personarse y acreditar continuamente su situación e identidad. Simultáneamente, y en la medida en que actúa también con determinados recursos, se trata de delimitar el margen de maniobra del sujeto para responder a los prerrequisitos legales.

\section{Las cláusulas generales: la institucionalización de la diferencia}

Por su estructura y contenido, las 'Hojas informativas' responden al claro propósito de ser un compendio, un medio de comunicación funcional, y unas guías básicas destinadas a la acción. Delimitan de un modo sencillo lo admisible, en un momento y contexto político determinado ${ }^{7}$. Cada hoja trata de un tipo de autorización y consta de 4 grandes apartados, que van desde las regulaciones más generales hasta las pautas más concretas: 1. Normativa de aplicación; 2. Tipo de autorización; 3. Requisitos necesarios; y 4. Información sobre el procedimiento. Son documentos de fácil lectura y carentes de tecnicismos jurídicos, que resumen lo esencial, ahorran la consulta del texto que lo fundamenta, y están accesibles a cualquier persona que entienda el castellano.

En primer lugar, una acción característica de dichas normativas responde a un principio muy general ${ }^{8}$ : ordenar (diferenciando) a los ciudadanos en grupos y subgrupos en función de criterios variables, encargados de traducir y normalizar las principales opciones políticas del momento. En este sentido, resultan característicos los primeros criterios del preámbulo ('requisitos necesarios'), formulados en términos excluyentes.

En materia de inmigración y como los investigadores constatan muy habitualmente, el principio de división primario es el que instituye una diferencia fundacional, de un lado, entre los ciudadanos de la Comunidad Europea y los que no lo son ("No ser ciudadano de un Estado de la Unión Europea, del Espacio Económico Europeo o de Suiza, o familiar de ciudadanos de estos países a los que les sea de aplicación el régimen comunitario.") y, del otro, entre los extranjeros no comunitarios y los residentes. Ciertamente ambas divisiones no están presentadas del mismo modo. Mientras la primera clasificación es explícita, la segunda no lo es, ni precisa la composición poblacional; al remitir al contexto laboral nacional ("que la situación nacional de empleo permita

${ }^{7}$ La mayoría de las páginas webs consultadas han sido revisadas en Junio 2012.

${ }^{8} \mathrm{Al}$ decir esto, soy consciente de que se trata de un principio organizativo y cognitivo básico ya que uno de los objetivos de los artículos jurídicos consiste precisamente en regular cada caso, discriminando lo que une o diferencia. Asimismo también constituye el mecanismo selectivo utilizado en otros ámbitos, y con otros fines como, por ejemplo, las convocatorias públicas (cursillos, empleos...), etc. El hecho de destacarlo, pues, no significa que se considere específico o especialmente notorio sino que su aplicación tiene un efecto particular en relación al tema aquí ecomendaciones, otras veces comos recomendaciones, otras veces como requariospoblaciones inmigrantes.tratado. 
la contratación') ', la relación se establece de manera más solapada, general, externa, objetiva, como si fuera neutra. Lo que, en primera lectura y al tratarse de un (potencial) trabajador podría considerarse como una protección y defensa de los candidatos a la inmigración en tanto que eventuales 'beneficiarios' (ajustando la demanda a la oferta), queda claramente desmentido en cuanto se analizan las cláusulas subsiguientes que han de cumplirse para que las 'oportunidades' diseñadas en filigrana tengan efectividad. No sólo no se garantiza nada (apertura del mercado laboral, reserva de plaza...) que aparezca específicamente favorable a potenciales inmigrantes sino que, por el contrario, ha de demostrarse que la obtención de las autorizaciones no perjudica a la población autóctona.

'Que la situación nacional de empleo permita la contratación. Lo permite si:

a. La ocupación que va a desempeñar el trabajador en la empresa está incluida en el catálogo de ocupaciones de difícil cobertura que el Servicio Público de Empleo Estatal publica trimestralmente.

b. La Oficina de Extranjería competente considere que no se ha podido cubrir el puesto de trabajo a tenor del certificado que el Servicio Público de Empleo emite sobre la gestión de la oferta de empleo. (Fuente: Autorización inicial de residencia temporal y trabajo por cuenta ajena, $6^{\circ}$ requisito)

La cita muestra como formulaciones banales y aparentemente intranscendentes están construidas de tal manera que ya contienen y marcan una manera de representarse y tratar al futuro trabajador que, pese a las denegaciones, presenta afinidades con, y puede generar, prácticas sociales o discursos discriminatorios... Así, la importancia del criterio utilizado está doblemente resaltada por las condiciones que han de darse para ser admitida la contratación y por la intervención de la Oficina de extranjería que tiene que ratificarlo. Dicho de otro modo, el sistema de preferencias que está en la base de la reglamentación no sólo diferencia de antemano al inmigrante de la población residente sino que le coloca en una posición, por definición, secundaria y subsidiaria con respecto a ésta.

Otros cuatro requisitos, también de corte jurídico y presentes en todos los tipos de autorización, completan los anteriores. Formulados en términos negativos y restrictivos, su característica distintiva es que están directamente relacionados con la trayectoria

${ }^{9}$ Existen dos modalidades más de autorización: la 'inicial de residencia temporal no lucrativa' que solicitan 'los extranjeros desde su país de origen' y les deja 'residir en España sin realizar actividad laboral.' Para esto, el solicitante debe acreditar que 'tiene medios económicos necesarios para sufragar los gastos de estancia y regreso y, en su caso, los de sus familiares, de acuerdo con las siguientes cuantías: Para su sostenimiento mensualmente el $400 \%$ del IPREM, que en este año 2012 asciende a 2.130,04 euros. Para el sostenimiento de cada uno de sus familiares, el 100\% del IPREM que en este año 2012 asciende a 532,51 euros. La otra modalidad es una 'autorización inicial de residencia temporal y trabajo por cuenta propia' y parece apuntar a cuadros o profesionales especialistas. 
personal pasada y, como si de una consecuencia natural se tratara, con la capacidad de acción futura del titular. Tres de ellos distinguen a los sujetos atendiendo, esta vez, a la legitimidad de las condiciones de entrada en el país: 'No encontrarse irregularmente en territorio español', 'No tener prohibida la entrada en España y no figurar como rechazable en el espacio territorial de países con los que España tenga firmado un convenio en tal sentido', 'No encontrarse, en su caso, dentro del plazo de compromiso de no retorno a España que el extranjero haya asumido al acogerse a un programa de retorno voluntario. ${ }^{\prime 10}$; mientras que el cuarto introduce una diferenciación en función de la existencia o no de antecedentes penales ( 'Carecer de antecedentes penales en España y en sus países anteriores de residencia por delitos existentes en el ordenamiento español. '). Prácticas y compromisos pasados se convierten así, si no en hechos irremediablemente imborrables (gracias a la prescripción del delito o a haber sido cumplida la pena...), al menos en limitaciones que reducen a priori la libertad de movimientos y abren de facto la brecha para posibles obstáculos y apreciaciones negativas de parte de aquellos a los que corresponda resolver el caso ${ }^{11}$.

Por consiguiente, desde sus preámbulos, la normativa no es sólo proteccionista con respecto a los moradores del país, sino que efectúa un doble marcaje discriminatorio. De un lado, convierte la pertenencia a una nación no comunitaria en algo semejante a un estigma: la procedencia nacional se transforma en un rasgo definitorio del sujeto; no sólo determina el marco legal al que puede optar objetivamente, sino que le coloca en una situación de dependencia que, o bien, escapa de manera casi irreversible a su capacidad de acción e intervención ${ }^{12}$; o bien convierte una decisión o actuación anteriores en pasos (casi) imborrables y cuyo resultado está enquistado y, a menudo también, naturalizado ${ }^{13}$. Por otro lado, des-individualiza y despersonaliza al individuo, reducién-

${ }^{10}$ En caso de vuelta voluntaria, el beneficiario contrae el compromiso de no volver a España antes de tres años.

${ }^{11}$ En este sentido, recordemos que un expediente de penales es especialmente gravoso y puede perseguir al sujeto de por vida, incluso después de haber prescrito. La ausencia de respuesta, el 'silencio administrativo' amparado por la ley, constituye así la mejor salida 'legal' para un caso como éste.

${ }^{12}$ El constructo de las características, sobre el cual nos llaman la atención Du Bois, Sayad o Stuart Hall, queda interesadamente invisibilizado

${ }^{13}$ Se va observando que la decisión de nacionalizarse no es baladí e implica consecuencias diversas que los agentes sociales tienen que sopesar (y suelen sopesar) atentamente. Aún así, ocurre regularmente que topan, en determinados casos, con consecuencias inesperadas. Por ejemplo, el hecho de que un inmigrante, nacionalizado, no pueda matricularse en un curso que responde a su perfil laboral y pueda hacerlo, sin embargo, en otros que no coincidan con sus probabilidades objetivas de encontrar trabajo. Asistí así en varias circunstancias, durante el trabajo de campo, a escenas en las que los candidatos reivindicaban su origen, alguno aduciendo irónicamente a falta de poder hacer otra cosa, que 'la mitad de su cuerpo era español y la otra [del país donde nació]'. La respuesta más común suele ser en este caso, y como ya apuntaba Sayad (1999), repartir los roles y posibilidades, naturalizándose sólo uno de los miembros de la pareja. A falta de 
dole - como muchos observadores señalan con respecto a los inmigrantes no comunitarios - a una de sus facetas, roles o habilidades, a su capacidad de operar como fuerza de trabajo (fundamentalmente, al servicio de otros). La relación contractual constituye así la principal matriz no sólo en torno a la cual giran todas las demás autorizaciones, sino también la que va dictando unos modos perdurables de insertarse, acomodarse y relacionarse con los demás.

En cualquier caso y considerados en conjunto, estos prerrequisitos definen un perfil particular de emigrante y potencial inmigrante: una persona a la que se presume como respetuosa de la legalidad en vigor en el país receptor y dispuesta, desde el momento en el que inicia los trámites, a amoldarse al y, más adelante, quedarse en, el mero papel de trabajador subalterno con el que se le asocia indefectiblemente. Además, y pese a ser parte de una enumeración lineal junto a otras condiciones, el carácter general de los prerrequisitos muestra su estatus particular: son los preámbulos que condicionan y dan el 'derecho' virtual a acceder al objeto concreto de la autorización (residencia, trabajo, reagrupación familiar...), en los términos en los que queda especificado en los apartados subsiguientes (y cuyo número y naturaleza varían en función del objetivo perseguido).

\section{Las cláusulas específicas: modelos culturales e inserción social}

Bajo la apariencia de definir los márgenes que permiten a priori la autorización, las cláusulas más específicas que estipulan las condiciones a las que tiene que responder la demanda — reforzada por la documentación a aportar a título de justificativo-, ponen de relieve simultáneamente elecciones culturales de otros órdenes a las cuales el inmigrante se tiene que adaptar y que, por lo tanto, van encauzando (en parte) su propia acción. Se ha señalado anteriormente como las relativas al empleo ya figuran como precondición a lo demás. Otro ejemplo muy significativo lo proporciona la 'autorización de residencia temporal por reagrupación familiar'. En este caso, dos tipos de consideraciones legales conllevan un marcado sesgo cultural, tanto desde el punto de vista social como material.

poder detenerse ahora sobre estas cuestiones, conviene recordar que — como es de sobra conocido — ni tan siquiera la adquisición de la nacionalidad, de lograrla, consigue liberar a la persona del estigma que pesa sobre su origen, desde el punto de vista del ciudadano autóctono. 


\subsection{Definición del modelo familiar}

Una condición se refiere a la composición de la familia, e implica expresamente una clara reafirmación de la familia nuclear, conyugal y monógama, y una definición de la dependencia intergeneracional más acorde con la legislación en vigor en el país anfitrión que con los criterios del de origen.

El familiar reagrupado podrá ser:

- Cónyuge o persona con la que el reagrupante mantenga una relación de afectividad análoga a la conyugal. En ningún caso podrá ser reagrupado más de un cónyuge o pareja. En el supuesto de estar casado o ser pareja por segunda o posterior vez, se deberá acreditar la disolución y la situación del anterior cónyuge o pareja y sus familiares en cuanto a la vivienda común, la pensión al cónyuge o pareja y los hijos. (..)

- Hijos del reagrupante y del cónyuge o pareja, incluidos los adoptados (...), menores de dieciocho años o discapacitados que no sean objetivamente capaces de proveer a sus propias necesidades (..)

- Ascendiente en primer grado del reagrupante residente de larga duración, o de su cónyuge o pareja, cuando estén a su cargo, sean mayores de sesenta y cinco años y existan razones que justifiquen la necesidad de autorizar la residencia en España.(...)

En este sentido, la normativa constituye no sólo una invitación a amoldarse a la estructura familiar considerada como legítima y de validez universal, así como una imposición de la definición de la verdad, sino también un procedimiento que conlleva una intromisión institucional en la vida privada de los demandantes. No obstante y más allá de la imposición cultural, lo más importante radica en que — contrariamente a lo que se hace con la población autóctona - cada una de las circunstancias tiene que ser rigurosamente comprobable mediante una autentificación muy pormenorizada de la veracidad de los hechos y las situaciones que pudieran derivarse de ellos. La monitorización de las prácticas sociales es total. La situación tiene que ser objetivada mediante la aportación de documentos que atestigüen la conformidad y tengan determinadas características: ser escritos, elaborados por organismos competentes en la materia o ante personas reconocidas para ello (sellos oficiales, comprobantes, dictámenes judiciales, compulsas...), sistemáticos (en el sentido de que no dejen ningún resquicio a la duda) y tener - cuando haga falta - la necesaria cobertura temporal. Presente y pasado personales y colectivos tienen, pues, que converger de tal manera que las circunstancias individuales y familiares de las personas involucradas cuadren perfectamente con la definición de lo admitido como legítimo en la sociedad receptora. 


\subsection{Las condiciones de habitabilidad}

El segundo tipo de exigencias legales para la reagrupación familiar revalida aquellos mismos principios al tiempo que añade otra fuente de imposición que limita el margen de acción de los inmigrantes y, en cambio, abre unos criterios suplementarios de discrecionalidad que conciernen, en particular, a las características de la vivienda y a la definición de los medios de vida mínimos.

» Tener medios económicos suficientes para atender las necesidades de la familia. Se podrán computar los ingresos aportados por el cónyuge u otro familiar en línea directa y primer grado residente en España que conviva con el reagrupante. Las cuantías mínimas son las siguientes (..)

» Disponer de vivienda adecuada.

La documentación a aportar para esto último hace más explícito cómo ha de entenderse:

Para ello deberá adjuntar informe expedido por el órgano competente de la Comunidad Autónoma del lugar de residencia del reagrupante. El informe podrá ser emitido por la Corporación Local (..) la documentación que se aporte deberá hacer referencia a: título que habilite para la ocupación de la vivienda, número de habitaciones, uso al que se destina cada una de las dependencias, número de personas que la habitan y condiciones de habitabilidad y equipamiento. (..)

El 'modelo orientativo de informe' puesto a disposición por el Ministerio en la página $w_{e b}{ }^{14}$ es aún más preciso en la medida en que especifica 'el contenido mínimo que debería incluir'. De buenas a primeras, el documento parece más destinado a constatar que a evaluar: localización de la vivienda, condiciones de apropiación; la habitabilidad y el equipamiento se refieren al agua, gas, electricidad. Se apunta la presencia o ausencia de determinados servicios, se registran los usos de las habitaciones, se computa el número de personas, de camas... Los apartados más abiertamente evaluativos conciernen a las condiciones higiénicas, así como la ventilación e iluminación, proponiendo para ambos apartados una respuesta dicotómica (sí o no) sobre la 'adecuación' que completa un espacio abierto destinado a posibles comentarios. Lo que no consta, sin embargo, son los criterios últimos en los que debe basarse el juicio 'favorable' o 'desfavorable' consignado al final. Tampoco quedan explícitamente mencionadas algunas exigencias (como la existencia de cocina y cuarto de baño, o el hecho de que no pueda haber en la

$14<$ http://extranjeros.empleo.gob.es/es/informacioninteres/Informes_CCAA_Entidades_locales/Informe_vivienda_adecuada/ $>$. 
vivienda una persona ajena a la familia nuclear, etc.) que, sin embargo parecen ser (al menos en ciertos municipios) criterios frecuentemente aducidos.

Los datos que se acaban de exponer resultan útiles para poner de relieve no sólo la imposición de unos usos culturales que no necesariamente responden a las pautas de vida y necesidades objetivas y subjetivas de los inmigrantes, sino también para vislumbrar lo que éstos tienen que hacer para adecuarse al perfil deseado, generado por modos de ver y de hacer, diferentes y extraños, en mayor o menor medida.

La relectura de las hojas informativas desde una perspectiva más pragmática, en efecto, hace entrever cómo van dictando una serie de tareas de diferente índole que son de obligatorio cumplimiento pese a no figurar explicitado en ninguna parte. Éstas, a su vez, presentan eventuales dificultades, cuyos efectos, restrictivos y disuasorios, se van sumando: unas tienen que ver con el conocimiento de la normativa y de los recursos, desplazamientos y gestiones (registro civil, servicio de extranjería, juzgados), solicitudes y permisos (DNE, residencia, inscripción en el censo municipal, trabajo, paro, seguridad social, salida del país), legalización de situaciones de hecho (matrimonio, divorcio, patria potestad, dependencia y certificados de discapacidad...); otras obligan a manejarse y organizar los tiempos: la planificación de viajes y estancias (personal, cónyuge, hijos, padres), la sumisión a los horarios (trabajo, escuela, oficinas de servicios sociales), la asunción de los plazos y demoras, la conservación prolongada de los justificantes (billetes de viaje, resguardos, duplicados, documentos de identidad, contratos de trabajo y de alquiler, escrituras de propiedad, etc.); se incentiva la búsqueda de un trabajo formal y de una vivienda 'adecuada', y a hacerse cargo de contratar la luz o el gas; se fomenta el cumplimiento de obligaciones (impuestos, cuotas...); se estimulan actividades: la inscripción de los hijos menores de edad en el colegio, el aprendizaje de informática y de Internet o del idioma local, la asistencia a cursillos, la captación de fondos y ayudas; el requerimiento de la intervención de intermediarios (mediadores, trabajadores sociales, traductores...). En tanto que son hechos y tareas cuya necesidad y rendimiento no son siempre inmediatos pero vienen impuestos por la administración, los individuos tienen que aprender a darles importancia e incorporarlos dentro de sus hábitos de vida, con el fin de responder de ello cuando se precise.

Nótese, sin embargo, que no todo implica necesariamente una enculturación y ruptura radical con respecto a los hábitos y valores propios. Algunas prácticas, incluso, adquieren importancia en ambos países (de emigración y de inmigración) de manera distintiva. Así, el ejemplo anterior del reagrupamiento de los padres muestra como hechos que van formando parte de valores y obligaciones familiares y comunitarias ligadas al país de origen, como puede ser el envío de remesas de dinero, abre — siempre que se pueda demostrar objetivamente enseñando los justificantes - la posibilidad de reagrupar a los progenitores, al ser considerados como pruebas de la dependencia. Los distintos usos del mismo hecho acarrean cambios tanto prácticos como simbólicos: el deber (personal) familiar (que pertenece al círculo de lo privado) se convierte en algo 
público del que el sujeto debe poder rendir cuentas ante un agente externo, guardando y enseñando las pruebas.

\section{Prácticas legítimas y procedimientos de contención de la inmigración}

Las cláusulas exigidas y los trámites obligan a constituir un expediente voluminoso, y que lleva tiempo, tanto en el momento de presentar la solicitud como después de la resolución, en caso de haber sido favorable. Así, son dignos de destacar dos cuestiones, ellas mismas entrelazadas: en primer lugar, el control de los plazos y el carácter temporal y progresivo de las autorizaciones - con lo que implica de multiplicación de los controles- $-y$, en segundo lugar, la creciente ampliación de las exigencias a medida que transcurre el tiempo y se amplía la duración de los permisos.

La comparación de los permisos más corrientes y paradigmáticos a los que los inmigrantes no comunitarios recurren (o tienen que recurrir), muestra dos rasgos. Primero, los plazos de resolución varían entre 45 días y 3 meses $^{15}$. Segundo y sobre todo, el 'silencio administrativo' o facultad que tiene la administración de no responder a una solicitud, tiene un alcance completamente distinto: mientras la falta de respuesta a una primera autorización debe ser interpretada como una denegación, se la considera como una aceptación en el caso de renovaciones y de residencia de larga duración. Contrariamente a lo que podría suponerse, esto probablemente no responda a una relajación del control sino, más bien, al aumento y a las características de las pruebas que han de superarse para ello: en efecto, el análisis más pormenorizado de los requisitos y documentos de comprobación muestra que se introducen nuevos requisitos y que, además, éstos dependen no sólo de la intervención de un número mayor de agentes sociales sino también de la implicación de instituciones ajenas al contenido nominal, directo, de la petición: la residencia y el trabajo. La renovación de la autorización de 'residencia temporal y trabajo por cuenta ajena', o de la 'residencia por reagrupación familiar' es paradigmática a este respecto. En ambos casos, una de las condiciones obligatorias es 'acreditar la escolarización de los menores a su cargo en edad de escolarización', mediante la aportación de un informe 'emitido por las autoridades competentes, autonómicas o estatales, o del centro educativo' . Asimismo, también se señala, con formulaciones parecidas, la posibilidad (potestativa) de aportar un 'informe de integración' emitido por la Comunidad Autónoma del lugar de residencia en el que conste 'el esfuerzo de integración del extranjero (Hoja Informativa $\mathrm{n}^{\circ}$ 15). Para ello, y según consta en la Hoja Informativa $\mathrm{n}^{\mathrm{o}} 18$, se sugiere que el informe de cuenta de 'la participación en acciones formativas y el conocimiento de las lenguas oficiales'. En resumidas cuentas,

${ }^{15}$ Dicha demora puede, a veces, generar problemas específicos a nivel personal o familiar, que se traducen en incertidumbre, desgaste emocional y, también, en gastos suplementarios. 
estas nuevas trabas parecen indicar que mientras la documentación permita acreditar la situación, probablemente ya no se considere necesario contestar.

Sin embargo, dichos requerimientos o simples recomendaciones, cuyo nexo con el objeto de la 'autorización' queda lejano y bastante oblicuo, ponen de relieve la presencia e incidencia de un imaginario socio-político sobre la inserción social asociado implícitamente a la residencia prolongada, y considerado de obligado cumplimiento de parte del inmigrante y su familia. En cambio, la normativa no deja indicio alguno que permita averiguar la importancia que tienen realmente estos datos; más bien la imprecisión al respecto deja abierta unos márgenes de discrecionalidad difícilmente recurribles; en efecto, debido al mero hecho de ser evocado, es previsible que sea un elemento que, si es utilizado, pueda inclinar favorable o desfavorablemente la valoración final de quiénes informen sobre el caso y, por último, de los que tomen la decisión final ${ }^{16}$. Recíprocamente, no es difícil imaginar que el que la normativa señale estas condiciones plantea las bases para que el inmigrante que esté informado de ello procure responder (al menos aparentemente) al modelo.

La transitoriedad impuesta de las autorizaciones (primero, un año, renovable; luego dos años, etc...) respondería presumiblemente, en zonas sometidas a una fuerte inmigración, a lo que los residentes (trabajadores sociales, políticos, vecinos o empresarios) atribuyen a menudo a la 'inestabilidad' de la población transeúnte. A lo largo del trabajo de campo, varias personas señalaron la versatilidad de los modos de vida de los inmigrantes que relacionan con los cambios de trabajo, con el que no se pretenda 'echar raíces' sino ganar dinero ('acudiendo al mejor postor'), o también con rasgos considerados como casi atávicos. Los cambios incesantes de lugar de residencia (pueblo, casa), de número de teléfono, de las personas con las que comparten la vivienda... son temas que autóctonos y, sobre todo, responsables públicos denuncian para explicar las dificultades de gestión (imprecisiones del censo de población, absentismo escolar, dificultad de localización de los interesados...). Desde la perspectiva, pues, de la administración, el paso obligado por diferentes etapas (años de residencia, estabilidad laboral) parece cumplir una doble función: meritoria, en el sentido de que se le exige al inmigrante que demuestre curricularmente su interés y empeño, su contribución a la sociedad mediante su inserción laboral y social, sus aportaciones a las cotizaciones de la Seguridad Social, el cumplimiento de sus obligaciones cívicas pagando los impuestos, su aceptación de las reglas locales y, finalmente, su dominio del idioma; y legitimadora ya que, en estas condiciones, la autorización que se le otorga eventualmente no se presenta como un acto unilateral sino como algo legítimo que se enmarca dentro de un modelo de intercambio, acreditado por las 'pruebas' de una integración lograda con tesón: implica una inversión en tiempo (calculado en número de años de estancia) y en hechos, modos de

${ }^{16}$ A nivel local, trabajadores sociales y, por encima de ellos, en la jerarquía, concejales o, incluso, alcaldes 
hacer y de estar ( si no necesariamente de ver), que se pueden interpretar como objetivaciones de la 'voluntad' por parte del inmigrante y como un reconocimiento de, y adhesión a, las formas de vida de la sociedad anfitriona. Los límites entre la idea positiva del inmigrante entendido como un operario cuyo trabajo se necesita y la negativa del intruso que 'quita el trabajo a los españoles' están muy bien reflejados en una práctica como el 'contrato en origen' ${ }^{17}$, cuyo compromiso se acaba con la temporada activa sin condicionar el futuro.

No obstante, la estrategia más eficaz y potencialmente disuasoria se da cuando las condiciones de posibilidad de la entrada o la permanencia de un extranjero en el territorio nacional recaen sobre terceros. Mediante unas exigencias que se presentan como benévolas y legítimas ${ }^{18}$, se ejerce un control que no afecta tanto (o no sólo) a un potencial defraudador como, más directamente, al inmigrante que espera cumplir sus expectativas de trabajar o de juntarse con la familia. Las 'autorizaciones de residencia temporal y de trabajo por cuenta ajena' son la mejor muestra de que el logro de un contrato de trabajo no constituye el único imperativo ni la sola dificultad a superar.

Sirva a título de ejemplo lo que tiene que aportar un empresario que acceda a contratar a un trabajador que no se halle ni resida en España. Como requisitos previos, el empleador deberá

» estar inscrito en el régimen del sistema de Seguridad Social y encontrarse al corriente del cumplimiento de sus obligaciones tributarias y frente a la Seguridad Social.

» contar con medios económicos, materiales o personales suficientes para su proyecto empresarial y para hacer frente a las obligaciones asumidas en el contrato frente al trabajador (..).

Pero lo más determinante y gravoso concierne a la larga lista de documentos a entregar: identificación de la empresa, copia del NIF o NIE y, en su caso, copia de la escritura de constitución de la empresa debidamente registrada; documentación que identifique a la empresa; copia del documento público que acredite que el firmante de la solicitud de autorización ostenta la representación legal de la empresa; contrato de trabajo firmado copia de la declaración del IRPF, o del IVA, o del Impuesto de Sociedades o del informe de la vida laboral de la empresa (VILE), referido a los últimos tres años, memoria

17 'Autorización temporal de residencia y trabajo' comprometido por el empresario que recluta la mano de obra en el propio lugar de origen y le ofrece vivienda y trabajo durante 10 meses, con la condición de que retorne a su país al concluirse el contrato laboral.

${ }^{18}$ Como el asegurarse de que el inmigrante disponga de un alojamiento adecuado para reagrupar a su familia, o que un empresario demuestre tener efectivamente la capacidad de emplearle y sufragarle el salario prometido. 
descriptiva de la ocupación a realizar así como la "Documentación acreditativa de concurrir algún supuesto de no consideración de la situación nacional de empleo".

Como estos datos demuestran, la puesta en marcha del proyecto migratorio $-\mathrm{y}$ su prolongación - se ve dificultado de antemano, primero, por el hecho de que el empresario esté dispuesto a, aporte o pueda aportar, todos los documentos necesarios para que la solicitud llegue a buen término; y, en segundo lugar, porque, los datos exigidos deben ser juzgados fidedignos por la persona que otorga o no el permiso. Dicho de otro modo, desde sus inicios, el proyecto migratorio no depende stricto sensu del inmigrante $\mathrm{y}$ de su red habitual de relaciones ${ }^{19}$; aquel se tiene obligatoriamente que insertar dentro de una trama relacional externa (social, empresarial...) de la que va a depender en gran parte que tenga la fortuna de poder o no trabajar. Pero, al ligar la demanda con la intervención de personas ajenas, así como con criterios evaluativos que no controlan quienes presentan la solicitud (empresario, inmigrante...), las posibilidades de que fracase el intento e, incluso, de caer en la ilegalidad, se multiplican de manera exponencial. De hecho, las dificultades a las que se enfrentan los trabajadores por cuenta ajena extranjeros hoy en día no tienen tanto que ver con el mercado de trabajo (competencia laboral, salarios, cargas sociales) como con el control de la administración sobre las empresas al obligarlas a aportar información detallada de su situación económica y fiscal. Como apuntan varios observadores externos en términos parecidos, 'para lograr un contrato, tiene que haber una apuesta muy fuerte por parte del empresario, que pocos están dispuestos a hacer'.

A su vez, la 'autorización de reagrupación familiar' es ocasión de impedimentos que también escapan en parte de la capacidad de acción del inmigrante. Los casos analizados permiten identificar diferentes imponderables que llegan a crear situaciones difíciles de encarar. Es un proceso que tiene que iniciar el 're-agrupador', pero sobre el que tiene escaso control aparte de adaptarse a los marcos estipulados respetando los plazos fijados ${ }^{20}$.

Aún si el reagrupante tiene trabajo y puede demostrar que dispone de medios de vida suficientes para mantener a los futuros reagrupados, la solicitud exige la intervención de varias instancias. Al Ayuntamiento le compite confirmar que el solicitante está empadronado y dar el visto bueno; a la policía local hacer el informe sobre la vivienda al que me he referido anteriormente, mientras el trabajador social debe redactar el de integración, del que dependerá (gracias a la firma de un superior en la jerarquía

${ }^{19}$ Uno no puede hacer menos que recordar el análisis de Lahire (2005: 343) sobre las condiciones que permiten fabricar a un hombre 'autónomo'. Incluso en un caso tan privilegiado como puede parecer la escuela, el autor muestra cómo la autonomía" no significa en absoluto "independencia absoluta" o "libertad individual" frente a los constreñimientos sociales" sino que se construye y 'supone una dependencia de dispositivos objetivados que es necesario apropiarse' para lograr dicha autonomía.

${ }^{20}$ Se puede, eventualmente, lograr acelerar el proceso pero el resultado depende de las redes sociales y, en última instancia, de la receptividad de las personas de las que depende la resolución. 
administrativa) la decisión última. La coordinación entre las distintas instancias institucionales obliga a saber anticipar y hacer los trámites de tal manera que coincidan los plazos fijados por cada instancia con el exigido para obtener el permiso. No obstante, el mero cumplimiento de los trámites oficiales conlleva riesgos. Incluso en el caso del informe de vivienda, la dependencia de terceros no se limita a los agentes de los servicios públicos. Por ejemplo, parece ocurrir a menudo que el Ayuntamiento no pueda acreditar que el solicitante esté sólo en la vivienda debido a que los anteriores inquilinos no se han dado de baja o no han rescindido su contrato de alquiler. La existencia de estas y otras situaciones - probablemente muy variadas - ilustran cómo lo que se achaca a veces a la falta de previsión o la dificultad de amoldarse a la lógica administrativa deriva bien sea del desconocimiento o del hiato entre lo oficial y lo escrito, y la práctica social (donde incurren dificultades circunstanciales imprevistas).

A fortiori, los hechos de esta índole no sólo someten a los inmigrantes dictándoles en parte su proceder, sino que fomentan el tener que acudir a, y a buscar la colaboración de, cuantas personas puedan, en virtud de su posición personal o institucional (empleador, propietario, centros escolares, Servicios Sociales Comunitarios, Ayuntamiento, Policía local...), acreditar — contorneando incluso la legalidad — aquello que escapa de las competencias del agente social. Una doble sujeción pues: la que está asociada a la condición de inmigrante, y la que promueve el mantenimiento de la dependencia en el curso de la vida cotidiana.

\section{Expectativas y lógicas culturales}

La rigidez de la normativa y de los plazos que rigen las respuestas administrativas crea también situaciones conflictivas en las que se vislumbra el desajuste entre las expectativas y la realidad. Ocurre, por ejemplo, cuando interviene una circunstancia extraordinaria que requiere una solución rápida.

El ejemplo siguiente ${ }^{21}$ es muy ilustrativo del desfase tanto práctico como temporal que se inmiscuye en la vida cotidiana para atender y compatibilizar unas lealtades orientadas por principios antitéticos. A un señor, le han avisado que tiene que viajar urgentemente a su país, debido al estado físico de su madre y a que el hermano en casa de quien ella vive no está en condiciones psíquicas de atenderla. Por otro lado, al haber solicitado la renovación del permiso de residencia, es arriesgado marcharse de España antes de recibir la resolución. ¿Cómo lograr el permiso de salida sin perder los derechos adquiridos? Se trata de una situación de apremio que reúne el deber familiar con el sufrimiento, y a los que, indudablemente, la persona que atiende el caso puede

\footnotetext{
${ }^{21}$ Observación en un servicio municipal de inmigración (Julio 2012).
} 
ser sensible ${ }^{22}$. Sin embargo, en virtud de su función de intermediaria, ésta enumera la documentación que debe aportar para demostrar que la solicitud de regreso 'responde [efectivamente] a una situación de necesidad':

» fotocopia del DNE

» certificado médico que ateste el estado de salud de la madre;

» copia del libro de familia

» certificado de nacimiento de él y de su hermano (para verificar que son hijos de la misma persona);

» certificado de matrimonio de su hermano;

» certificado de defunción de la cuñada.

La respuesta inmediata del hombre deja patente su desconcierto ('...$j$ sin estos documentos, no se puede viajar?'), y la sigue otra de corte dubitativo y crítico ('si no está aprobada [renovación del permiso de residencia] ¿por qué hacen pagar las tasas?'). El diálogo pone de relieve dos lógicas opuestas y difícilmente conciliables. Desde el punto de vista del empleado, el número y la naturaleza de los documentos enumerados pretendían prevenir cualquier rechazo posible (lo que equivalía, desde su perspectiva, a una manera de 'ganar tiempo' evitando demoras y eventuales disgustos) ${ }^{23}$. Pero esto chocaba con las dificultades que el peticionario pudiera encontrarse para conseguir recabar todos los documentos en un lapso de tiempo que le permitiera no demorar el viaje.

Los problemas que surgen no tienen que ser tan complejos para resultar ilustrativos. Lo habitual es que se trate más bien de cosas menores, acciones aparentemente intranscendentes, sin embargo, recurrentes. Pero todas tienden a objetivar la dificultad de encajar las acciones y decisiones dentro del marco oficial y/o legal.

Los ejemplos son de diferente naturaleza y enjundia: olvidar un documento, llegar a destiempo a una cita, solicitar un permiso in extremis, salir del país de vacaciones sin avisar previamente al paro, no mandar a los niños al colegio... Sistemas de disposiciones incorporadas y apreciaciones diferentes de la importancia y de la urgencia (Bourdieu 1991 [1981]), se combinan de tal manera que se multiplican los desencuentros entre formas de ver y de hacer, así como los malentendidos. En estas y otras situaciones (como aducen a menudo tanto los autóctonos como, a veces, los propios inmigrantes), no es infrecuente la utilización — por parte de éstos - de tácticas y estrategias de di-

${ }^{22}$ La observación en las ventanillas de los servicios administrativos lo documentan a menudo (Corcuff, 2012; Spire, 2008; Fischer y Spire, 2009). Y no está descartado pensar que el inmigrante, según la experiencia que tenga, nutra la esperanza de que las cosas se solucionen más fácilmente gracias a la compasión.

${ }^{23}$ De hecho, los consejos que las personas conocedoras de la dinámica administrativa suelen dar a los inmigrantes para asegurar la toma en consideración de su solicitud, muestran a saciedad la importancia de no dejar resquicio para la duda: por ejemplo, si hay que presentar copia del pasaporte o del libro de familia, fotocopiarlos enteros; sacar el certificado de nacimiento, procurarse también los de los padres, etc. 
simulación y de manipulación: invocación de olvidos o retrasos, cambios de fechas, pérdida de los papeles de identidad o de los comprobantes...; causas exculpatorias (modificación de plazos, presiones recibidas; trasiego de los trabajadores...; ); cambios de ventanillas y elección de centros o trabajadores conocidos por su mayor atención y comprensión.... Lo que algunos españoles catalogan a menudo como 'mentiras' o, incluso, de una manera menos complaciente, como formas de ser atávicas o culturales (reprobables desde nuestros parámetros culturales), constituye en situaciones de emergencia, para los agentes sociales directamente concernidos, formas de acción a mano para presionar e intentar vencer unas dificultades que, tal como están planteadas, resultan insuperables y que, muchas veces, ni comprenden ni acaban de aceptar.

\section{Conclusión}

En realidad, no cabe plantear dichos desencuentros como el simple resultado de la incomprensión y del choque cultural. Lo que está en juego son no sólo lógicas y hábitos diferentes, como acabo de señalar, sino más bien situaciones, prioridades y escalas de valores que entran en conflicto, dentro de unos espacios sociales en los que el inmigrante ocupa, por definición (como se veía al inicio del análisis), y de principio a fin (la normativa se especifica y retroalimenta), una posición subordinada y subalterna que se objetiva en una pluralidad de relaciones sociales diferentes: con el residente, el obrero autóctono, el empresario, el propietario de la vivienda, el empleado público (en el ámbito local, provincial o estatal), el director o tutor de la escuela, etc. Mediante distintos microprocesos (aparentemente inocuos), éstos construyen, en el día a día, lo que consiste $\mathrm{ser}$ un inmigrante (no comunitario) en la práctica: cuál es su estatus en la sociedad, cómo se relaciona con los demás y, en particular, cómo muchas de sus acciones están no sólo monitorizadas sino también comprobadas y sometidas a formas recurrentes de control.

El problema que la normativa examinada plantea, evidentemente, no es original. Las ciencias sociales contemporáneas han hecho suya la idea de que al instituir la arbitrariedad se la legitima (así como su aplicación) dándole, además, la eficacia simbólica conferida por la referencia a la ley. Sin embargo, esta constatación no debe esconder sus consecuencias más flagrantes y deletéreas: en este caso, y de manera tan banal como en otros, el hecho de que se imponga como una evidencia y se acaben naturalizando tanto los criterios utilizados como su producto. ¿Quién - dentro de la sociedad receptora- dudaría de que no se puede equiparar a un extranjero con un residente? $\mathrm{O}$ ¿de que es normal darle un empleo al segundo en detrimento del primero? O, también que el inmigrante que quiere vivir aquí tiene que insertarse compartiendo los modos de vida y la lengua del país? Etc. Todo esto resulta familiar, resuena a sentido común fuertemente asentado, y a formas relativamente compartidas de ver las cosas en los países 
occidentales (máxime en un contexto de crisis económica y social). La reglamentación parece dirigirse, pues, a dos tipos de interlocutores/lectores diferentes: explícitamente, al inmigrante que tiene la expectativa de estar cubierto por la legislación (superando la criba inicial); e, implícitamente, al habitante nacional que puede verse respaldado por unas normativas que le dan preferencia con respecto al extranjero.

Lo visto a lo largo de estas líneas coincide con una constante de la política inmigratoria en el contexto actual. Fassin advierte primero que en la era de los derechos humanos 'el tratamiento de los otros, incluso cuando pone en marcha unas lógicas profundamente desigualitarias, no toma nunca la forma de una denegación, incluso implícita, de lo que les convierte en hombres' (Fassin, 2005: 41) sino 'otras modalidades de gestión de lo intolerable'. Y, aludiendo a la conocida distinción de Foucault (2003 [1997]) entre los que hay que 'hacer vivir' y los que hay que 'dejar morir', recuerda los dos principios en los que dicho autor se basa: 'un principio de diferencia, que instituye la separación entre aquellos cuya vida es sagrada y aquellos cuyas vidas pueden ser sacrificadas; y un principio de indiferencia, que subordina la protección de los segundos a la ausencia de riesgos para los primeros.' (Fassin, 2005: 43). Pues bien, se constata que las Hojas informativas, objeto principal de este análisis, siguen esta misma pauta cognitiva y social. Mientras las cláusulas generales instauran el principio de diferencia, las más específicas - en particular lo relativo al trabajo - constituyen una aplicación clara del de indiferencia, entendido de dicho modo.

\section{Bibliografía}

BouRdieu, P. (1991 [1981]): El sentido práctico, Madrid, Taurus Humanidades.

CACHÓN, L. (2002): "La formación de la España inmigrante: mercado y ciudadanía”, Revista Española de Investigaciones Sociológicas, 97, pp. 95-126.

CACHÓN, L. (2006): "Discriminación étnica en el mercado laboral”, Puntos de Vista, 5, pp. $7-26$.

CACHÓN, L. (2008): "La integración de y con los inmigrantes en España: debates teóricos, políticas y diversidad territorial», Política y Sociedad, 45 (1), pp. 205-235.

Corcuff, Ph. (2012): "De la domination à ce qui lui échappe: le cas de la compassion" en

Où est passée la critique sociale? Penser le global au croisement des savoirs, Paris, La découverte.

Devillard, M.J. (2014): "La prueba de la inmigración: ciudadanía, derechos humanos y fuentes de vulnerabilidad", Awraq. Revista de análisis y pensamiento sobre el mundo árabe e islámico contemporáneo, 10 (2), pp. 39-61.

DuBAR, C. (2002 [2000]): La crisis de las identidades. La interpretación de una mutación, Barcelona, Edicions Bellaterra. 
Du BoIs, W.E.B. (1996 [1986]): The souls of Black folk essays and sketches, Charlottesville, Va, University of Virginia Library

Euias, N. (1965): The established and the outsiders, London, Sage Publications.

FASSIN, D. (2005): “L'ordre moral du monde”, en Fassin D. y P. Bourdelais, Les constructions de l'intolérable. Études d'anthropologie sur les frontières de l'espace moral, Paris, Ed. La Découverte, pp. 17-50.

FASSIN, D. y A. MoRICE (2001): "Les épreuves de l'irrégularité: les sans-papiers, entre déni d'existence et reconquête d'un statut", en Schnapper D., Exclusions au cour de la cité, Paris, Anthropos, pp. 261-309.

Fischer, N. y A. SPIRE (2009): “L'État face aux illégalismes”, Politix, 87 (3), pp. 7-20.

Foucault, M. (2001[1982]): "El sujeto y el poder", en Dreyfus H. y P. Rabinow, Michel Foucault. Más allá del estructuralismo y de la hermenéutica, Buenos Aires, Edición Nueva Visión, pp. 227-244.

Foucault, M. (2003 [1997]): Hay que defender la sociedad, Madrid, Akal.

Gil Araujo, S. (2008): Las argucias de la integración. Políticas migratorias, construcción nacional y cuestión social, Madrid, IEPALA.

IzQuiERDo, A. (2001): "Epílogo. La política hacia dentro o el sistema de inmigración irregular en España”, en Sassen S., ¿Perdiendo el control? La soberanía en la era de la globalización, Barcelona, Edicions Bellaterra, pp. 107-137.

Lahire, B. (2005): L'esprit sociologique, Paris, Éditions La Découverte.

Laparra, M. (ed.), (2003): Extranjeros en el purgatorio. Integración social de los inmigrantes en el espacio local, Barcelona, Edicions Bellaterra.

Martínez Veiga, U. (2011): “La encuesta del cis, 2008”, en Inmigrantes africanos, racismo, desempleo y pobreza, Barcelona, Icaria.

Martuccelli, D. (2006): Forgé par l'épreuve. L'individu dans la France contemporaine, París, Fayard.

Mezzadra, S. (2005): Derecho de fuga. Migraciones, ciudadanía y globalización, Madrid, Traficantes de sueños.

Mitl, S. (1987): "Minimal Selves", en Appignanesi, L. (dir.), Identity: The Real Me, London, Institute of Contemporary Arts.

NAïr, S. (2002): "Cinco ideas falsas sobre la inmigración en España”, El País, 16 de mayo de 2002.

SASSEN, S., (2001): ¿Perdiendo el control? La soberanía en la era de la globalización, Barcelona, Edicions Bellaterra.

SAYAD, A. (2010 [1999]): La doble ausencia. De las ilusiones del emigrado a los padecimientos del inmigrado, Barcelona, Anthropos. 
Secretaría General de Inmigración y Emigración, "Información sobre trámites y procedimientos - Hojas informativas". Disponible en:

$<\mathrm{http}$ //extranjeros.empleo.gob.es/es/InformacionInteres/InformacionProcedimientos/ index.html $>$ [Consulta 8 de octubre de 2012]

SPIRE, A. (2008): Accueillir ou reconduire. Enquête sur les guichets d'immigration, París, Raisons d'Agir. 